
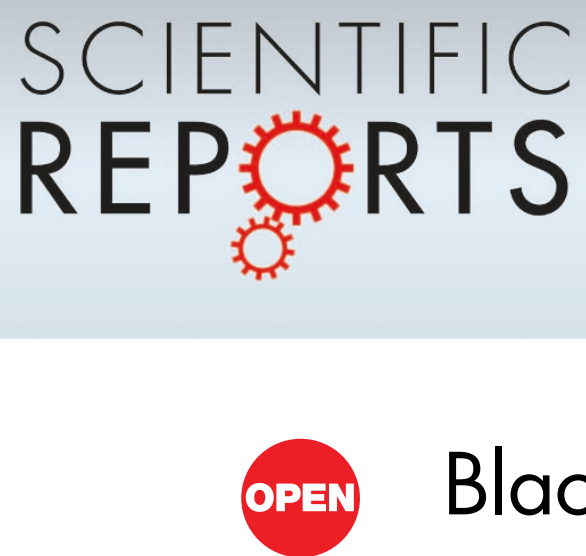

\title{
Black carbon aerosol size in snow
}

\author{
J. P. Schwarz ${ }^{1,2}$, R. S. Gao' , A. E. Perring ${ }^{1,2}$, J. R. Spackman ${ }^{3,4}$ \& D. W. Fahey ${ }^{1,2}$
}

SUBJECT AREAS:

ATMOSPHERIC

DYNAMICS

CRYOSPHERIC SCIENCE

APPLIED PHYSICS

ATMOSPHERIC CHEMISTRY

Received

2 October 2012

Accepted

4 February 2013

Published

1 March 2013

Correspondence and requests for materials should be addressed to J.P.S. (Joshua.p. schwarz@noaa.gov)
${ }^{1}$ Chemical Sciences Division, Earth System Research Laboratory, National Oceanic and Atmospheric Administration, Boulder, Colorado 80305 USA, ${ }^{2}$ Cooperative Institute for Research in Environmental Sciences, University of Colorado, Boulder, Colorado 80309 USA, ${ }^{3}$ Physical Sciences Division, Earth System Research Laboratory, National Oceanic and Atmospheric Administration, Boulder, Colorado 80305 USA, ${ }^{4}$ Science \& Technology Corp, Boulder, Colorado, 80305 USA.

The effect of anthropogenic black carbon (BC) aerosol on snow is of enduring interest due to its consequences for climate forcing. Until now, too little attention has been focused on BC's size in snow, an important parameter affecting $\mathrm{BC}$ light absorption in snow. Here we present first observations of this parameter, revealing that $\mathrm{BC}$ can be shifted to larger sizes in snow than are typically seen in the atmosphere, in part due to the processes associated with $\mathrm{BC}$ removal from the atmosphere. Mie theory analysis indicates a corresponding reduction in BC absorption in snow of $40 \%$, making BC size in snow the dominant source of uncertainty in BC's absorption properties for calculations of BC's snow albedo climate forcing. The shift reduces estimated $\mathrm{BC}$ global mean snow forcing by $30 \%$, and has scientific implications for our understanding of snow albedo and the processing of atmospheric BC aerosol in snowfall.

C, a byproduct of combustion, has a unique role as a climate forcing agent. It absorbs the most solar light per unit mass of any atmospheric aerosol material, as indicated by its large mass absorption cross section (MAC). The effect of anthropogenic $\mathrm{BC}$ aerosol on snow albedo and lifetime is the subject of enduring interest ${ }^{1,2}$ due to its consequences for regional and global climate forcing ${ }^{3}$. When deposited to snow, $\mathrm{BC}$ produces a definitive decrease in albedo ${ }^{4,5}$ that is believed to have directly contributed, for example, to the reduction of Himalayan glaciers ${ }^{6}$. BC's small size and initial tendency to hydrophobia enhances its propensity to be transported to remote regions, such as the Arctic ${ }^{7}$, where its impact on snow albedo is predicted to significantly alter the radiative balance of the planet ${ }^{3}$. Human activity produces a large fraction of emitted $\mathrm{BC}$, which as an atmospheric pollutant has serious health ${ }^{8}$ impacts, making $\mathrm{BC}$ mitigation for both climate change and public health an important subject of scientific and political consideration. Hence, the need to understand the uncertainties and mechanisms of BC's climate interactions is great.

$\mathrm{MAC}$ is often used to quantify the extent to which $\mathrm{BC}$ absorbs solar radiation because it allows convenient translation between $\mathrm{BC}$ mass and its absorption and, as such, is a useful parameter for modelers and experimentalists. BC MAC in the atmosphere depends on the extent of internal mixing of the $\mathrm{BC}$ with other materials ${ }^{9}$, a relationship that is the focus of much research ${ }^{10}$. MAC also depends on the size of the $\mathrm{BC}$ particles because particles tend to absorb light in amounts proportional to their mass when their diameters are small with respect to the light's wavelength, and in the limit of large size, only in amounts proportional to their surface area. Atmospheric BC size distributions have only recently become commonly ${ }^{11-13}$, available, and almost uniformly show that atmospheric $\mathrm{BC}$ is small enough to absorb light in amounts linearly proportional to its mass.

Generally, BC's atmospheric MAC values are adopted for use in snow. For example, measurements of light absorption in snow have been translated to $\mathrm{BC}$ mass concentration in snow via an assumed $M A C$ value ${ }^{14}$ based on atmospheric $\mathrm{BC}$, and an atmospheric $\mathrm{BC}$ MAC value has been used as the basis for a global model estimate of the radiative forcing of snow-bound $\mathrm{BC}^{3}$. In the results shown here, $\mathrm{BC}$ 's size is found to be larger in snow than in the atmosphere, in part due to the influences of the processes associated with removal of $\mathrm{BC}$ from the atmosphere. Mie theory analysis indicates that BC's atmospheric MAC value may be inappropriately large for use in snow.

\section{Results}

Our results were obtained with a Single Particle Soot Photometer (SP2), an instrument that detects the refractory $\mathrm{BC}$ mass content and mixing state of individual aerosol particles ${ }^{15}$. The SP2 quantifies BC mass, not the physical size of the $\mathrm{BC}$ material, so each observed mass is translated to a volume-equivalent diameter (VED) by assuming a $1.8 \mathrm{~g} / \mathrm{cc}$ void-free density. Hence, VED size distributions are referred to as "mass size distributions". The SP2 can be used in conjunction with a nebulizer for determination of $\mathrm{BC}$ mass concentration and mass size distribution in liquid samples (in this case melted snow), even those with significant dust contamination, as discussed in detail elsewhere ${ }^{16}$, and briefly in the Methods section. 
A system that characterizes BC mass size distribution in snowmelt will only give accurate information about $\mathrm{BC}$ size in snow if the melting process does not change the mass size distribution. Here, we assume that neither melting of the snow, nor nebulization of the resulting melt, causes $\mathrm{BC}$ agglomeration that would shift the $\mathrm{BC}$ distribution to larger sizes. This assumption is well supported: 1) the mass concentrations we observed in snow were low $(<\sim$ $100 \mathrm{ng}-\mathrm{BC} / \mathrm{g}$-snow), so the $\mathrm{BC}$ in snow inhabited less than $0.1 \times$ $10^{-6}$ of the volume of water present and agglomeration in liquid was unlikely; 2) laboratory testing showed that the BC mass size distribution was fairly stable within melted snow over timescales of $\sim 1 \mathrm{~d}$, directly indicating low enough concentration to avoid significant agglomeration in the liquid phase on this time scale, and at least 24 times as long as was taken to perform the measurements discussed here; 3) laboratory tests also showed that individual thaw/refreeze cycles of laboratory BC standards in water only changed the BC mass size distribution slightly, in a manner suggesting that even when $\mathrm{BC}$ was "pressed" into smaller volumes by the exclusionary effect of ice crystal formation, only a small mass fraction $(<5 \%)$ agglomerated. This result is valid for the concentrations observed in the snow melt and suggests $<5 \%$ shift in MAC for a single freeze/thaw cycle of fallen snow; and 4) laboratory BC standards in water revealed no sign ( $<5 \%$ of total BC mass) of agglomeration even at much higher (x 50) concentrations than typical snow samples, validating the performance of the nebulizer.

Based on the observed small agglomeration effect in thaw/refreeze cycles, we hypothesize that, with repetition, such cycles occurring in ambient snow could significantly affect the BC mass size distribution. It follows that the first laboratory melting of a snow sample is expected to provide the most accurate size distribution of the $\mathrm{BC}$ contained in the snow at the time of sampling, and the earliest sampling after snowfall will provide the mass size distribution closest to that in the snow when deposited on the surface. For this reason, a single average mass size distribution of snow-bound BC is presented as determined only from optimally handled samples.

Figure 1 shows a mass size distribution averaged from five local snow samples collected from three Colorado snowfalls within $60 \mathrm{~km}$ of Denver, CO, in both semi-rural and rural areas (black line, with whiskers showing the standard deviation of the five individual distributions around the average). These were directly sampled within minutes of their first melt in the laboratory with the nebulizer/SP2 system (for up to 40 minutes). Also shown in Figure 1 are two mass size distributions for atmospheric BC. Although there is some variability in the size distribution of BC observed in the atmosphere with SP2s, the distribution is typically close to a pure lognormal function with a mass median diameter of $\sim 220 \mathrm{~nm}$ VED or smaller. The distribution with the smallest BC median size in Figure 1 (red circles and fit, labeled "urban") is from ambient atmospheric BC observed in the Los Angeles basin during an entire flight of the NOAA WP-3D research aircraft in the CalNex 2010 project (unpublished data obtained with the NOAA SP2). In this dataset, the BC median size was small enough that a significant fraction of the total accumulation mode mass could not be detected by the SP2, as shown by the lognormal fit. Less than $1 \%$ of the mass of this mode was associated with BC cores larger than $600 \mathrm{~nm}$ VED based on the fit. The next larger median size (blue line with squares, labeled "remote") is associated with the distribution of atmospheric BC observed over the remote regions of the Pacific Ocean during the 2009 HIPPO campaign ${ }^{17}$. This size distribution is very similar to that measured in fresh biomass burning plumes observed in 2006 in Texas $^{13}$ (not shown), and also has less than $1 \%$ of its mass associated with $\mathrm{BC}>600 \mathrm{~nm}$ VED based on log-normal fitting. An exceptionally large atmospheric distribution was measured with an SP2 in a Southern China ${ }^{18}$. There, a secondary mode of atmospheric BC at larger size was observed in the polluted boundary layer in the region of a mega city, yet still only $6 \%$ of BC mass was found in sizes larger than $600 \mathrm{~nm}$. This Chinese distribution probably provides an upper bound for the contribution of non-lognormal "shoulders" of BC at masses larger than the primary peak, as seen in the urban data of Figure 1. Urban-sourced atmospheric BC measured during the Texas campaign ${ }^{13}$ was intermediate in size between the atmospheric distributions shown. BC mass size distributions measured in the air in Colorado (not shown) also typically have this intermediate size, and hence fit comfortably within the small particle range where MAC is not strongly dependent on $\mathrm{BC}$ size.

BC mass size distributions are not available in the air masses that generated the snowfall examined here. The snowmelt-BC mass size distribution has a primary mode fairly similar to the remote atmospheric distribution, but deviates from a log-normal distribution with a significant shoulder of mass in refractory BC particulate larger

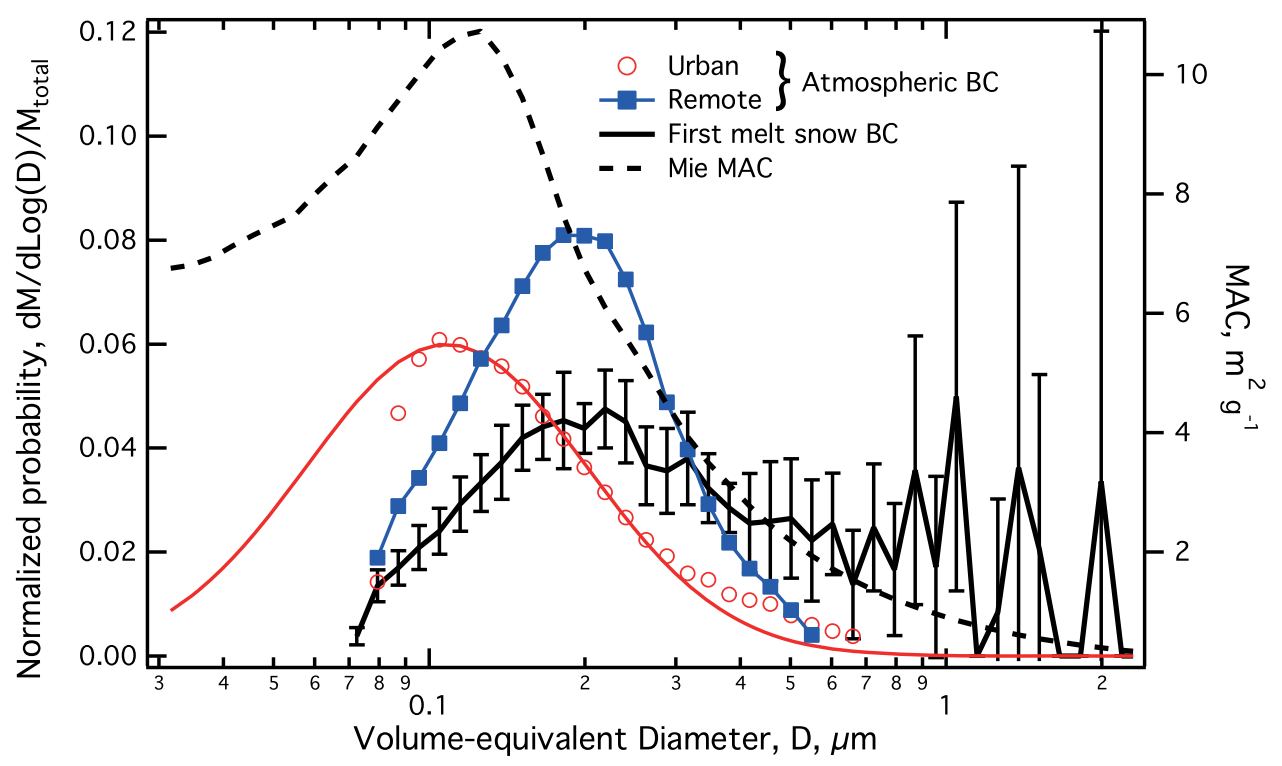

Figure $1 \mid$ BC mass size distributions and mass absorption cross section (MAC). The normalized BC mass size distributions from the atmosphere (remote and urban) and from the five snow samples, as a single average with whiskers representing the variation in the underlying distributions (standard deviation) are plotted against the left vertical axis. The MAC is plotted with a dashed line against the right vertical axis, and was calculated for $460 \mathrm{~nm}$ light and $\mathrm{BC}$ with index of refraction $(2.26,-1.26)$. 
than $~ 500 \mathrm{~nm}$ VED, with $28 \%$ of its mass in BC larger than $600 \mathrm{~nm}$ VED. Included in this set of snow samples was a single measurement of extremely fresh snow, collected near our laboratory the morning after the snowfall (which occurred at night). This sample revealed that larger BC particles than typical were already present in the snow. It is unlikely that this snow experienced even a single thaw/freeze cycle before its laboratory evaluation; hence, this indicates that the shift in BC size occurred in the atmosphere, and likely was due to significant agglomeration and/or size selection of BC during the formation of the snow in the atmosphere. Note that although BC is dilute in snow, its concentration in freshly nucleated ice crystals or in freshly frozen particles in the atmosphere may be much higher. Thus, $\mathrm{BC}$ agglomeration via freezing of $\mathrm{BC}$-containing droplets in the atmosphere may be more likely than via freeze cycles of fallen snow. $\mathrm{We}$ are not able to distinguish growth or selection of $\mathrm{BC}$ that occurred in the atmosphere from agglomeration that may have occurred after temperature cycles of fallen snow, or during dry deposition of BC independent of snowfall as in ${ }^{19}$.

In addition to the local snow samples, 31 snow samples from Arctic areas sampled far from sources were provided by Stephen Warren (Dept. of Atmospheric Science, Univ. of Washington, Seattle, WA USA) and Sarah Doherty (JISAO, Univ. of Washington, Seattle, WA USA). As discussed in the Methods section, although the Arctic mass size distributions are not directly presented here due to less than optimal handling, the majority of these samples showed some evidence of size distribution shift to larger sizes, although some did not; on average they revealed $17 \%$ of the BC mass from cores larger than $600 \mathrm{~nm}$ with a standard deviation of $24 \%$, substantially more than seen even in the exceptional Chinese mass size distribution ${ }^{18}$ mentioned above. Hence these remote results support our basic conclusions based on the small set of local samples and suggest that even very remote snow may contain BC particles larger than expected based on atmospheric size distributions.

We have run simple calculations of particle coagulation and sizedependent removal to assess the likelihood that these processes could explain the large BC particles observed in snow. For high atmospheric concentrations of BC aloft in Colorado we modeled 200 accumulation-mode particles (without BC content) with 100 accumulation mode BC cores (log-normally distributed around number median diameter of $100 \mathrm{~nm}$ VED, equivalent to $\sim 200 \mathrm{~nm}$ VED mass median diameter) in each cubic centimeter of air. Over twelve hours, a time scale that serves as an upper bound for aerosol interaction during precipitation events, only negligible changes in $\mathrm{BC}$ size distribution were predicted due to coagulation $(\ll 1 \mathrm{~nm}$ shift in mass median diameter).

Size dependent removal of atmospheric BC has been observed ${ }^{13}$, in which BC mass distributions (based on the published number size distributions) had a median mass diameter of $\sim 200 \mathrm{~nm}$ in air that underwent wet removal, in contrast with a mass median diameter of $219 \mathrm{~nm}$ in air that had not experienced wet removal (with geometric standard deviations of 1.51 and 1.64 , respectively). The precipitated BC mass size distribution can be calculated from these values along with the reported $\sim 80 \%$ removal efficiency that caused the shift in these distributions. This analysis shows that the precipitated BC would be shifted only slightly to larger size with mass median diameter $\sim 220 \mathrm{~nm}$ and still less than $1 \%$ of its mass in BC cores larger than $600 \mathrm{~nm}$. Hence, neither size dependent removal nor coagulation are likely to completely explain the larger BC found in snow. Hence, we hypothesize that one or more complex interaction are also at play, perhaps involving some combination of the following: 1) the agglomeration in the atmosphere of water-bound BC; 2) long-duration in-cloud residence times and prolonged exposure to collisioncoalescence in a small fraction of cloud parcels (as has been modeled in Arctic stratus ${ }^{20}$ ) that could enhance BC content within individual droplets; 3 ) agglomeration of snow bound $\mathrm{BC}$ due to freeze cycles on the ground. Note that $\mathrm{BC}$ collected via impaction of snowflakes is not likely to agglomerate without repeated freeze cycles due to the extreme volume dilution in the ice (as discussed above). To test this hypothesis, both rigorous modeling and extensive measurements of $\mathrm{BC}$ size in snow of different ages will be needed.

The difference observed in BC's size range between the snow and the ambient atmosphere can cause a reduction of BC MAC in snow because larger BC particles tend to absorb light less efficiently per unit mass than smaller particles (Figure 1, dashed line). To quantify the magnitude of this reduction, MAC was calculated for the different BC size distributions shown in Figure 1 with Mie theory ${ }^{21}$. This approach assumes a simple picture of $\mathrm{BC}$ particles as spherules with values for density $\left(1.8 \mathrm{~g} \mathrm{~cm}^{3}\right)$ and complex index of refraction $(\mathrm{n}=$ $(2.26,-1.26))$ based on optimized index and density for optical modeling determined from ambient BC in Tokyo $^{22}$. These values provide reasonable agreement between Mie theory scattering and that observed for fullerene soot, a calibration material with properties very close to that of ambient Tokyo BC and ambient BC observed in Switzerland ${ }^{22,23}$. The Mie calculations were performed for light at $460 \mathrm{~nm}$, the wavelength at which BC is estimated to most strongly affect snow albedo ${ }^{24}$. For the urban mass size distribution in Figure 1, the log-normal fit was used as the basis to calculate the MAC.

The sensitivities of the calculated MAC values to the index of refraction and light wavelength were explored as shown in Table 1. The MAC values from the remote atmosphere and first-melt snow distributions are shown as ratios to that from the urban distribution (shown separately in the second row). Substantial decreases in MAC are calculated for $\mathrm{BC}$ in the size range observed in snow compared to that seen in the atmosphere, up to a $40 \%$ decrease. In contrast, the atmospheric MAC values differ by only $\sim 10 \%$. The exceptional Chinese atmospheric BC size distribution ${ }^{18}$ discussed above had a MAC $\sim 25 \%$ lower than that of the urban distribution. The differences between the typical atmospheric and first-melt snow MAC values are much larger than the differences that occur with differing choice of index and wavelength. Larger uncertainties associated with the Mie estimate of the MAC changes arise from the fact that the actual morphology of the BC particles in snow is not known. For example, if the BC were in highly fractal shapes, as it tends to be upon emission from fossil fuel sources, then it is likely that there would be no shift in MAC between snow and atmospheric BC (as in the Raleigh/Debye/Gans approximation for atmospheric $\left.\mathrm{BC}^{25}\right)$. This extreme is unlikely, as BC tends to collapse from a fractal to a denser morphology with increasing age and processing ${ }^{26,27}$. Nevertheless, the Mie theory analysis presented here likely provides an upper

Table 1 MAC values and ratios calculated with Mie theory ${ }^{a}$

\begin{tabular}{lcccc} 
Index of refraction & $(2.26,-1.26)$ & $(2.26,-1.26)$ & $(2,-1)$ & $(\mathbf{2 . 2 6 , - 1 . 2 6 )}$ \\
\hline Wavelength, $\mathrm{nm}$ & 550 & 500 & 550 & $\mathbf{4 6 0}$ \\
Urban MAC, $\mathrm{m}^{2} \mathrm{~g}^{-1}$ & 7.1 & 7.7 & 6.2 & $\mathbf{8 . 3 5}$ \\
Remote/urban atmosphere ratio & 0.97 & 0.92 & 0.94 & $\mathbf{0 . 8 8}$ \\
First-melt snow/urban ratio & 0.67 & 0.63 & 0.67 & $\mathbf{0 . 5 8}$
\end{tabular}

The ratios of refractory BC MAC calculated for remote or first-melt snow size distributions to that calculated from the urban size distribution (CalNex). The calculation was repeated with different values for absorbing wavelength and the index of refraction of bare $\mathrm{BC}$ spheres in Mie theory. The right-most column represents our best estimate. 
estimate on the impact of BC size on snow-bound BC MAC for BC without optically significant coatings.

\section{Discussion}

Increased $\mathrm{BC}$ size and decreased $\mathrm{BC} \mathrm{MAC}$ in snow have implications for both modeling and measurement communities. BC MAC is often used as a fundamental model input, and has a strong effect on model estimates of BC's radiative forcing. BC's global mean snow albedo forcing, as calculated by the Snow, Ice, and Aerosol Radiative (SNICR) model coupled with a $\mathrm{GCM}^{3}$, is linearly dependent on BC MAC over a $\sim \pm 20 \%$ range, with a constant of proportionality of 0.75 . This indicates that an overestimate of BC MAC of $40 \%$ would result in a $\sim 30 \%$ overestimate in the forcing. Determinations of $\mathrm{BC}$ mass loading in snow that depend on absorption measurements (e.g. 11) will underestimate the loadings if an atmospherically relevant MAC value is used.

This sensitivity highlights the need for new work to harmonize measurements with model treatments of BC's size transformation in snowfall, and to improve knowledge of both BC size and MAC, and their variability, in snow around the world, as well as the processes that influence them.

\section{Methods}

To use the SP2 to quantify particulate concentration and size distribution in liquid, the efficiency with which a nebulizer aerosolizes the various sized particulates in the liquid must be determined. We used a new technique ${ }^{16}$ to characterize this efficiency based on polystyrene latex sphere (PSL) concentration standards The PSLs were aerosolized from known concentrations in water, and the efficiency with which the nebulizer aerosolized them into a given volume of air was observed to depend on particle diameter, with larger diameter particles less well aerosolized. We assumed that losses scaled with particle stopping distance, not some other particle size/shape parameter. Thus, particle stopping distance, a measure of the inertia of particles that is often used in calculations of particle losses in tubing/sampling/etc., was used to connect the results from the PSLs to BC particles. Stopping distance $S$ is defined as:

$$
S=\frac{\rho D^{2} C_{C}}{18 \eta} U
$$

where $\rho$ is the density of the particle, $\eta$ is the air dynamic viscosity, $C_{C}$ is the Cunningham slip correction factor, and $D$ is the particle diameter. $\mathrm{BC}$ stopping distance was calculated from the SP2-measured BC masses taken in conjunction with published BC density estimates ${ }^{28,29}$, and the measured BC size distributions were scaled to normalize those efficiencies. As discussed in a technical paper ${ }^{16}$, for the nebulizer used here, these shifts did not result in large changes in distributions, but rather only in changes corresponding to a $20 \%$ shift in the estimate of BC mass loadings.

Due to the presence of large $\mathrm{BC}$ particle masses in snow melt, the sensitivity of the SP2 to larger particles than it typically quantifies in the ambient atmosphere had to be determined. This was accomplished, as discussed in full detail in the technical paper ${ }^{16}$, via an extrapolation of the SP2 calibration curve to large mass based on previous results $^{16,28,29}$. Briefly, other experimentalists ${ }^{28}$ have measured the non-linearity of SP2 response to $\mathrm{BC}$ mass for larger particles up to volume-equivalent diameters of $600 \mathrm{~nm}$; the response is linear over most of the range where BC mass is typically observed in the air at smaller sizes. We calibrated the SP2 in the linear regime and then adopted the published non-linearity dependences to extend the calibration to large sizes, up to $2000 \mathrm{~nm}$, for which calibration information is not available (and will be difficult to obtain). In terms of BC mass size distributions and MAC, discussed in the main text, the uncertainties associated with these manipulations for the specific nebulizer used in the study and the SP2 calibration lead to minor shifts in mass size distribution at large size and only a $\sim 10 \%$ contribution to MAC uncertainty. Note that the SP2 is quite insensitive to dust in comparison to its sensitivity to BC. Examination of the vaporization temperatures of the large particles detected here confirmed their BC composition. The dust contribution influences BC determinations primarily at small sizes $(<400 \mathrm{~nm})$, and, for the samples used here, had an insignificant effect on the measured BC mass size distributions. Hence the overall uncertainty in the $\mathrm{BC}$ mass size distributions examined here are not large enough to substantially affect the underlying conclusions of this manuscript.

The majority of the 31 Arctic samples tested showed enhanced populations of large $\mathrm{BC}$, consistent with the local snow results. However, these samples experienced two thaw/refreeze cycles before first sampling in the laboratory with the SP2, with 1 day or less total spent thawed before sampling by the SP2, and thus are not of optimal quality. To explore the effects of the additional freeze cycles and time spent thawed, we replicated this behavior on a local snow sample, and on laboratory standards of BC in liquid. The results indicated that, although the $\mathrm{BC}$ mass concentration in the samples were affected at the level of $\sim 50 \%$, the mass size distribution shifted smaller amounts, ranging from no shift at all (for the laboratory standards), to slightly less than half the amount observed in the arctic samples compared to atmospheric BC (for the local snow). Hence we include these samples as supporting the likelihood that BC size in snow can be larger than in the atmosphere over large regions of the globe.

1. Warren, S. G. \& Wiscombe, W. J. A model for the spectral albedo of snow. II: Snow containing atmospheric aerosols. J. Atmos. Sci. 37 No. 12, 2734-2745 (1980).

2. Flanner, M. G. et al. Springtime warming and reduced snow cover from carbonaceous particles. Atmos. Chem. Phys. 9, 2481-2497 (2009).

3. Flanner, M. G., Zender, C. S., Randerson, J. T. \& Rasch, P. J. Present-day climate forcing and response from black carbon in snow. J. Geophys. Res. 112, D11202 (2007).

4. Hadley, O. L. \& Kirchstetter, T. W. Black carbon reduction of snow albedo. Nature Climate Change 2, 437-440 (2012).

5. Brandt, R. E., Warren, S. G. \& Clarke, A. D. A controlled snowmaking experiment testing the relation between black carbon content and reduction of snow albedo. J. Geophys. Res. 116, D08109 (2011).

6. Menon, S. et al. Black carbon aerosols and the third polar ice cap. Atmos. Chem. Phys. 10, 4559-4571 (2010).

7. Liu, J., Fan, S., Horowitz, L. W. \& Levy II, H. Evaluation of factors controlling longrange transport of black carbon to the Arctic. J. Geophys. Res. 116, D04307 (2011)

8. Highwood, E. J. \& Kinnersley, R. P. When smoke gets in our eyes: the multiple impacts of atmospheric black carbon on climate, air quality and health. Environment International 32 4, 560-566 (2006).

9. Schnaiter, M. C. et al. Absorption amplification of black carbon internally mixed with secondary organic aerosol. J. Geophys. Res. 110, D19204 (2005).

10. Cappa, C. D. et al. Radiative absorption enhancements due to the mixing state of atmospheric black carbon. Science 31, 337, 1078-1081 (2012).

11. Schwarz, J. P. et al. Single-particle measurements of midlatitude black carbon and light scattering aerosols from the boundary layer to the lower stratosphere. J. Geophys. Res. 111, D16207 (2006).

12. Schwarz, J. P. et al. Measurement of the mixing state, mass, and optical size of individual black carbon particles in urban and biomass burning emissions. Geophys. Res. Lett. 35, L13810 (2008).

13. Moteki, N. et al. Size dependence of wet removal of black carbon aerosols during transport from the boundary layer to the free troposphere. Geophys. Res. Lett. 39, L13802 (2012).

14. Doherty, S. J., Warren, S. G., Grenfell, T. C., Clarke, A. D. \& Brandt, R. E. Lightabsorbing impurities in Arctic snow. Atmos. Chem. Phys. 10, 11647-11680 (2010).

15. Schwarz, J. P. et al. Coatings and their enhancement of black-carbon light absorption in the tropical atmosphere. J. Geophys. Res. 113, D03203 (2008).

16. Schwarz, J. P.et al. Assessing recent measurement techniques for quantifying black carbon concentration in snow. Atmos. Meas. Tech 5, 2581-2592 (2012).

17. Schwarz, J. P. et al. Global-scale black carbon profiles observed in the remote atmosphere and compared to models. Geophys. Res. Lett. 37, L18812 (2010).

18. Huang, X.-F. et al. Black carbon measurements in the Pearl River Delta region of China. J. Geophys. Res. 116, D12 (2011).

19. Spackman, J. R. et al. Aircraft observations of enhancement and depletion of black carbon mass in the springtime. Arctic, Atmos. Chem. Phys. 10, 9667-9680 (2010).

20. Harrington, J. Y., Feingold, G. \& Cotton, W. R. Radiative impacts on the growth of a population of drops within simulated summertime Arctic stratus. JAS 57, 766-785 (2000)

21. Bohren, C. F. \& Huffman, D. R. [Absorption and scattering by a sphere] Absorption and scattering of light by small particles [82-104] (Wiley VCH, Weinheim, 2004)

22. Moteki, N., Kondo, Y. \& Nakamura, S. Method to Measure Refractive Indices of Small Nonspherical Particles: Application to Black Carbon Particles. J. Aerosol Sci. 41, 513-521 (2010)

23. Laborde, M. et al. Sensitivity of the Single Particle Soot Photometer to different black carbon types. Atmos. Meas. Tech. 5, 1031-1043 (2012).

24. Flanner, M. G., Liu, X., Zhou, C., Penner, J. E. \& Jiao, C. Enhanced solar energy absorption by internally-mixed black carbon in snow grains. Atmos. Chem. Phys. 12, 4699-4721 (2012).

25. Gao, R. S. et al. A Novel Method for Estimating Light-Scattering Properties of Soot Aerosols Using a Modified Single-Particle Soot Photometer. Aerosol Sci. Technol. 41,125-135 (2007).

26. Slowik, J. G. et al. Measurements of Morphology Changes of Fractal Soot Particles using Coating and Denuding Experiments: Implications for Optical Absorption and Atmospheric Lifetime. Aerosol Sci. Technol. 41, 734-750 (2007).

27. Fuller, K. A., Malm, W. C. \& Kreidenweis, S. M. Effects of mixing on extinction by carbonaceous particles. J. Geophys. Res. 104, 941-15, 954 (1999).

28. Moteki, N. \& Kondo, Y. Dependence of Laser-Induced Incandescence on Physical Properties of Black Carbon Aerosols: Measurements and Theoretical Interpretation. Aero. Sci. Technol. 44, 663-675 (2010).

29. Gysel, M., Laborde, M., Olfert, J. S., Subramanian, R. \& Gröhn, A. J. Effective density of Aquadag and fullerene soot black carbon reference materials used for SP2 calibration. Atmos. Meas. Tech. Discuss. 4, 4937-4955 (2011).

\section{Acknowledgements}

The authors thank Sarah J. Doherty and Steven G. Warren, University of Washington, for sharing stored Arctic snow samples and for discussion about BC in snow, and Graham Feingold, NOAA ESRL, for helpful insight into cloud dynamics. 


\section{Author contributions}

JPS performed the snow measurements and MAC calculations, and was the primary author of the manuscript; AEP performed the instrument calibrations and wrote the coagulation model code; JPS, AEP and JRS operated the instrument for the atmospheric measurements; RSG and DWF were part of the intellectual development of the work; all authors contributed to the manuscript.

\section{Additional information}

Competing financial interests: The authors declare no competing financial interests. License: This work is licensed under a Creative Commons

Attribution-NonCommercial-NoDerivs 3.0 Unported License. To view a copy of this license, visit http://creativecommons.org/licenses/by-nc-nd/3.0/

How to cite this article: Schwarz, J.P., Gao, R.S., Perring, A.E., Spackman, J.R. \& Fahey, D.W. Black carbon aerosol size in snow. Sci. Rep. 3, 1356; DOI:10.1038/srep01356 (2013). 